\title{
Fast valve power loss evaluation method for modular multi-level converter operating at high-frequency
}

\author{
Fen Tao ${ }^{1}$, Zhujun Xie ${ }^{2}$, Jie Cheng ${ }^{1}$, Chenghao Li' ${ }^{2}$ Lu Zhao ${ }^{1}$ and Jinyu Wen ${ }^{2 *}$
}

\begin{abstract}
There is no common accepted way for calculating the valve power loss of modular multilevel converter (MMC). Valve power loss estimation based on analytical calculation is inaccurate to address the switching power loss and valve power loss estimation based on detailed electro-magnetic simulation is of low speed. To solve this problem, a method of valve power loss estimation based on the detailed equivalent simulation model of MMC is proposed. Results of valve power loss analysis of 201 -level $500 \mathrm{MW}$ MMC operating at $50 \mathrm{~Hz} \sim 1000 \mathrm{~Hz}$ are presented. It is seen that the valve power loss of a MMC increased by 12,40 and $93 \%$ under $200 \mathrm{~Hz}, 500 \mathrm{~Hz}$ and $1000 \mathrm{~Hz}$ operating frequency. The article concludes that in a device with isolated inner AC system, MMC operating at higher frequency will be more competitive than typical $50 \mathrm{~Hz} / 60 \mathrm{~Hz} M M C$ with moderate increase of operating power loss and significant reduction of the size of the AC components.
\end{abstract}

Keywords: Modular multilevel converter (MMC), Medium-high frequency, Valve power loss, Conduction power loss, Switching power loss

\section{Introduction}

The Modular Multi-Level Converter (MMC) has been making its way for wide application in both medium and high voltage applications. The MMC is able to synthesize a very high quality sinusoidal waveform by generating a large number of voltage levels [1-3]. Each IGBT in the sub-modules(SM) is normally switched only at a equivalent frequency of $100-150 \mathrm{~Hz}$ under Nearest Level Modulation (NLM). As a result, the power loss can be reduced to about $1 \%$ per converter station [4].

Currently, there are no commonly accepted standards for determining the power loss for MMC. The IEC has a draft standard (IEC 62751) in preparation [5]. An intuitive way of obtaining the valve power loss valve power losses of a converter station is comparing the measured power at the AC side and the DC side. However, the difference between these two measured values is small, and a good accuracy will be very difficult to reach [5]. Also,

\footnotetext{
* Correspondence: jinyu.wen@hust.edu.cn

${ }^{2}$ State Key Laboratory of Advanced Electromagnetic Engineering and Technology (Huazhong University of Science and Technology), Wuhan, Hubei Province 430074, China

Full list of author information is available at the end of the article
}

such method is not able to observe the distribution of value power loss and the factors that impact valve power losses. For most cases, therefore, the losses have to be estimated from component characteristics, using suitable mathematical models of the converters [6]. From traditional PWM modulated two-level and three-level voltage source converter (VSC), the valve power loss can be obtained analytically $[7,8]$. valve power lossvalve power losses The analytical method requires variables such as power factor, dc voltage, valve current and switching occasion of the semiconductors.

For MMC, some of the necessary input parameters such as valve currents and switching occasions are difficult to be obtained by purely analytical methods [9]. Reference [10] proposed a method based on piece-wise analytical formulas to evaluate the valve power lossvalve power losses, and accurate conduction power loss can be obtained. But the additional switching loss caused by voltage balancing control is estimated to its upper limit, which makes power loss evaluation result of [10] conservative.

To achieve accurate valve power loss evaluation, electrical variables such as the valve currents and the firing 
pulses of each IGBT are required. Electro-magnetic simulations are therefore recommended to obtain these variables. Reference [11] proposed interpolating analytically integrable equations to calculate voltage and currents during the switching event so as to accurately represent the switching power losses. But such integrable equations are difficult to realize in simulation tools. By analyzing the simulated voltage and current waveforms, power losses are evaluated with different converter operation points in [12], where the detailed electro-magnetic simulation model of MMC was applied.

The method of [12] is accurate, except that it is based on detailed switching model of MMC and therefore the valve power loss estimation requires significant of simulation time. It may take one week to simulate 5-seconds dynamics of a 401-level MMC [13]. Therefore, the valve power loss evaluation based on detailed switching model is time consuming and inconvenient to analyze the impacts affecting valve power loss of MMC, which typically involves repeatedly simulation. To solve such challenges, a valve power loss evaluation method based on fast MMC simulation model is proposed in this paper.

Operating at ac frequency higher than $50 / 60 \mathrm{~Hz}, \mathrm{MMC}$ can significantly reduce the size of AC transformer, AC inductor and sub-module capacitors. Such high frequency MMC can bring great benefits to front-to-front connected $\mathrm{dc} / \mathrm{dc}$ converters [14] which consist of two ac/dc converters coupled by an AC transformer or other AC link such as LCL circuit. There are few literatures analyzing the valve power loss of MMC under high frequency operation [15]. Therefore, it would be beneficial to study the relationship between valve power loss and operating frequency.

In this paper, an accurate and fast valve power loss evaluation method is proposed based on detailed equivalent electro-magnetic simulation of MMC.

\section{Method}

\section{Average value model for power loss study Basic operating principles of $\mathrm{mmc}$}

Figure 1 (a) shows a three-phase MMC consisting of an upper arm and a lower arm for each phase unit, each arm has $\mathrm{N}$ half-bridge sub-modules (denoted as $\mathrm{SM}_{1}-\mathrm{SM}_{\mathrm{N}}$ ) and one inductor $\mathrm{L}$ in series. The topology and control method of MMC has been well studied in [16, 17].

To calculate valve power loss accurately, firing pulses for $T_{1}, T_{2}$, arm current and SM capacitor voltage are required from electro-magnetic simulation results. But, as pointed out in [13], detailed switch model of MMC costs excessively long simulation time. Thus, a fast simulation model of MMC is proposed as a substitution to obtain the above variables for valve power loss.

\section{Fast simulation model for $M M C$}

Figure 1 (b) shows schematic of the fast MMC simulation model (taking one phase as an example). In this model, each arm is represented by a controlled voltage source with the magnitude of $U_{\mathrm{arm}}$.

The user defined component 'Calculate SM Voltages' takes arm current $I_{\text {arm }}$ and firing pulse $S_{\mathrm{C}(1: \mathrm{N})}$ of each $\mathrm{SM}$ as the inputs to get capacitor voltage for each SM. The 'Modulation and Voltage Balancing Control' module takes reference voltage $U_{\text {ref }}$, arm current $I_{\text {arm }}$ and capacitor voltage $U_{\mathrm{C}(1: \mathrm{N})}$ as inputs to generate the firing pulses of each sub module [18].

The voltage of SM can be expressed as:

$$
U_{C i}(t)=U_{C i}(t-\Delta t)+\frac{S_{C i}}{C} \int_{t-\Delta T}^{t} I_{S M i}(\tau) d \tau
$$

In eq.(1), $\Delta t$ is the integration step, $U_{C i}(t)$ is the voltage of SM capacitor, $U_{C i}(t-\Delta t)$ is the SM voltage in previous integration, $S_{C i}$ is a signal function with values of 1 and 0 , which represents switch-on state and bypass state of SM, $I_{S M i}$ is the arm current flowing into SM.

By trapezoid integral:

$$
U_{C i}(t)=U_{C i}(t-\Delta t)+\frac{\Delta t}{2} \cdot \frac{S_{C i}}{C}\left(I_{\text {armA }}(t)+I_{\text {armA }}(t-\Delta t)\right)
$$

$I_{\text {armA }}$ is the upper arm current of phase A and it is the same of $I_{S M i}$.

The output voltage of number $i$ th SM is:

$$
U_{S M i}=U_{c o n i}+S_{C i} \cdot U_{C i}
$$

$U_{\text {coni }}$ is the on-state voltage of an IGBT or diode, it exhibits when device is in the conducting state. The onstate voltage depends on its current in a non-linear manner and it is usually represented as a piecewise-linear approximation [19] with a threshold voltage $U_{O}$ and a slope resistance $R_{c o n}$, as shown by equation (4):

$$
U_{\text {coni }}=R_{\text {coni }} \cdot I_{S M i}+U_{0 i}
$$

Depending on the directions of arm current and switch on/off state of SM, there are 4 values for $U_{c o n i}$ :

$$
U_{\text {coni }}=\left\{\begin{array}{l}
R_{\text {coni_D1 } 1} \cdot I_{S M i}+U_{0 i \_D 1}, I_{S M}>0 \text { and } S_{C}=1 \\
R_{\text {coni_T1 }} \cdot I_{S M i}-U_{0 i \_T 1}, I_{S M}<0 \text { and } S_{C}=1 \\
R_{\text {coni_T2 }} \cdot I_{S M i}+U_{0 i \_T 2}, I_{S M}>0 \text { and } S_{C}=0 \\
R_{\text {coni_D2 } 2} \cdot I_{S M i}-U_{0 i \_D 2}, I_{S M}<0 \text { and } S_{C}=0
\end{array}\right.
$$

By superposing voltage of the series SMs in one arm, the voltage output of upper arm of phase A can be expressed as: 


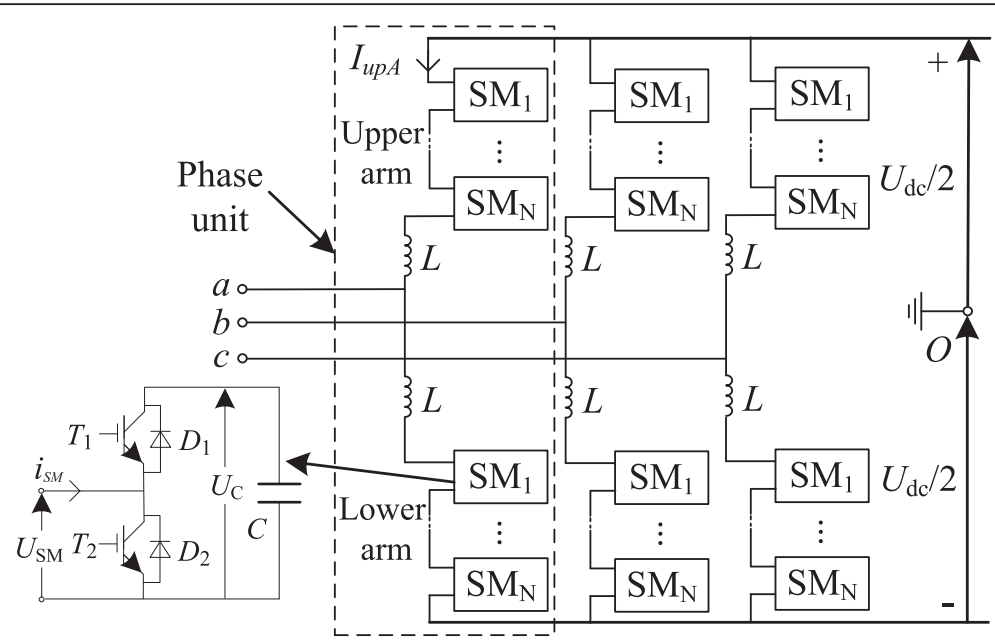

(a) Switch model of MMC

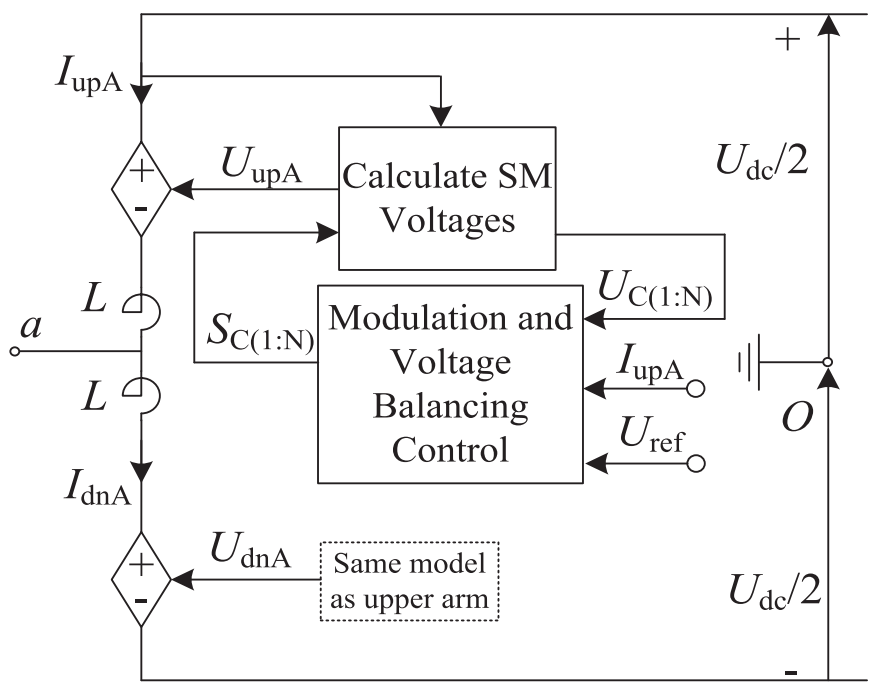

(b) Average model MMC with firing pulse

Fig. 1 Circuit diagram of a single phase of MMC

$$
U_{u p A}=\sum_{i=1}^{N} U_{S M i}=\sum_{i=1}^{N}\left(U_{c o n i}+S_{C i} \cdot U_{C i}\right)
$$

In.(6), $N$ is the number of SMs in one arm.

Taking this calculated voltage as reference value of the voltage controlled voltage source(VCVS) shown in Fig. 1 (b), a numerical arm of MMC can be established.

This fast simulation model is able to obtain almost identical simulation results as the detailed switching model while simulation speed can be improved by approximately 10,000 times. In addition, it provides the pulse signal of each IGBT, capacitor voltage of each SM and waveform of arm current for power loss study.

\section{Valve power loss calculation method based on fast simulation model \\ Categories of valve power losses}

The power losses are usually estimated from component characteristics, using suitable mathematical models of the converters. The valve power loss can be subdivided into 5 iterms:1) IGBT conduction losses; 2) diode conduction losses; 3) IGBT switching losses; 4) diode recovery losses; 5) IGBT and diode cut-off losses. The formulas for each item of valve power loss has been well 
developed in [4-8]. To be concise, they are listed in the Appendix.

\section{Junction temperature and parameters adjustment}

The valve power loss requires the parameters such as the threshold voltage, conduction resistance and switching energy of the power semiconductors (as presented in $(12,13,14,15,16,17,18,19$ and 20) in the Appendix). These parameters are related to the $\mathrm{PN}$ junction temperature of power semiconductors. In return, PN junction temperature also depends on the heat generated by loss power. Thus, to accurately estimate valve power loss, power loss and junction temperature of each device need to be calculated iteratively.

Since the junction temperature cannot be measured directly, it will be estimated using a thermal circuit as presented in literatures [12] and [19]. Input for the thermal circuit is the measured temperature of the heat sink while output is the estimated PN junction temperature.

Procedure of iterating the PN junction temperature can be described as follows:

1) The heat sink temperature will be measured and an initial value of $\mathrm{PN}$ junction temperature is given;

2) Based on the present PN junction temperature, parameters such as the threshold voltages, conduction resistance and switching energy will be calculated from the datasheet provided by the manufacture;

3) From the obtained parameters of step 2) and the simulated arm currents, sub-module capacitor voltages and the switching state of each sub-module, valve power loss of the power semiconductor will be estimated;

4) Based on the estimated valve power loss, the measured heat sink temperature and the thermal circuit of the power semiconductor, a new estimated $\mathrm{PN}$ junction temperature is obtained;

5) Substitute the obtained new PN junction temperature of step 4) into step 2) and repeat step 2) to 4) until the difference between the previous estimated $\mathrm{PN}$ junction temperature and the present estimated $\mathrm{PN}$ junction temperature falls within a pre-defined deviation

\section{Flow chart of valve power loss}

A common valve power loss program for MMC is designed in this paper. Flowchart of the program is shown in Fig. 2. It is based on Matlab/GUI with interface to PSCAD/EMTDC.

Firstly, simulation results of fast model in PSCAD are saved as. OUT file. Then the data of capacitor voltages $\left(U_{\mathrm{c}}\right)$, arm current $\left(I_{\mathrm{arm}}\right)$ and switching states of each submodules $\left(\mathrm{S}_{\mathrm{C}}\right)$ of the six arms will be read by the 'Valve

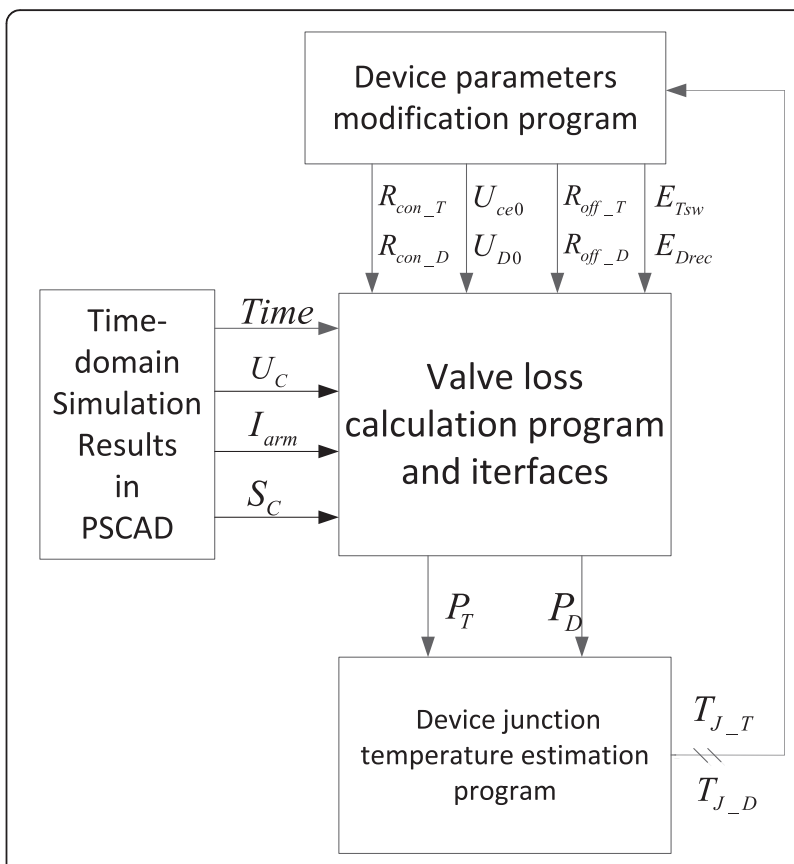

Fig. 2 Power loss calculation based on simulation and considering junction temperature feedback

power loss calculation program' developed in Matlab. By reading initial parameters of semiconductor devices from 'Device parameters modification program', the power loss and junction temperature of each device can be estimated.

In the next calculation step, the initial parameters of devices are adjusted according to its junction temperature. And then, the power losses are calculated again with the simulation results data of this time step.

Because the switching pattern of each sub-module varies from one fundamental circle to the next, the loss calculation result should be the average value of several fundamental cycles (time duration per circle is $20 \mathrm{~ms}$ for $50 \mathrm{~Hz}$ ac frequency).

In the simulation results reading program mentioned above, the operating frequency on ac side of MMC can be recognized.

\section{Parameters design for high frequency MMC}

To ensure the valve power loss calculation results under different operation frequency are comparable, the value of SM capacitor and arm inductor should be designed commensurate to the operating frequency.

\section{Value of arm inductor against operating frequency} Though arm inductor can be designed to suppress inrush current in transient or suppress circulating current 


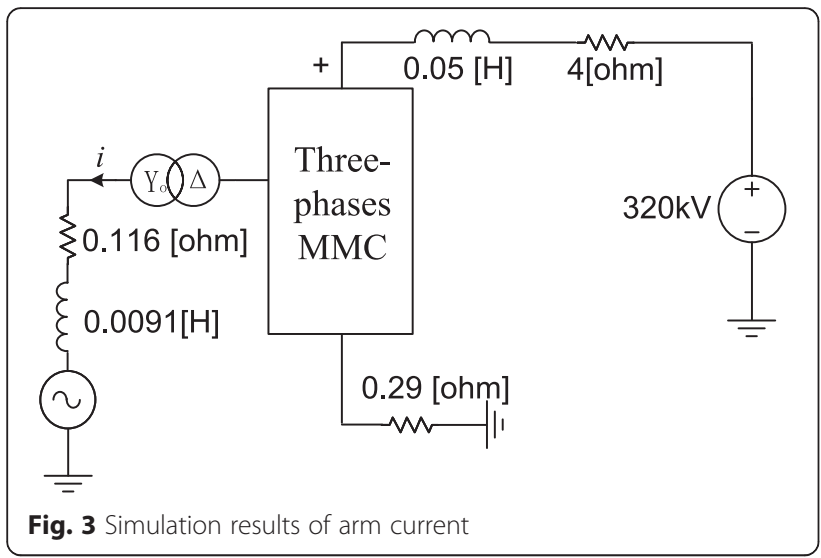

between the arms, it is usually seen as the connection inductor between ac grid and converter [20].

The apparent capacity (per unit) of connection inductor $X$ can be determined by:

$$
S_{L}(p u)=\frac{I_{N}^{2} X}{V_{N} I_{N}}=\left|\sin \delta_{N}\right|, \varphi=0
$$

For HVDC application, $\left|\delta_{N}\right|$ is usually set between $5.7^{\circ}$ and $17.5^{\circ}$. Then $\mathrm{S}_{\mathrm{L}(\mathrm{pu})}$ should be $0.1 \sim 0.3$, thus $X$ can be determined in the range of $0.1 \sim 0.3 \mathrm{pu}$.

Since the per unit value of arm inductor is constant, the actual inductance is inversely proportional to operating frequency. In the following high frequency $\mathrm{MMC}$ study, the arm inductance is adjusted according to the operating frequency to make sure that valve power loss calculation results are comparable.

\section{Value of SM capacitor against operating frequency}

The value of SM capacitor can be determined by the limitation of voltage fluctuation range, illustrated by:

$$
C_{0}=\frac{\Delta W_{S M}}{2 \varepsilon\left(U_{C}\right)^{2}}
$$

Where, $\varepsilon$ is maximum fluctuation limit percentage of SM voltage and it is usually set as $10 \% . \Delta W_{S M}$ is the fluctuant energy of the capacitor.

$$
\Delta W_{S M}(k)=\frac{2 P_{S}}{k N \omega_{0}}\left[1-\left(\frac{k \cos \varphi}{2}\right)^{2}\right]^{\frac{3}{2}}
$$

Where, $P_{S}$ is the apparent power of MMC and $\omega_{0}$ is operating angular frequency. $k$ represents voltage modulation ratio. Substitute eq. (9) into eq.(8), the capacitor of SM can be calculated by:
Table 1 Converter parameters and operation conditions

\begin{tabular}{lll}
\hline Parameters & Value & Comment \\
\hline Rated ac voltage & $220 \mathrm{kV}$ & Line-to-line \\
$\begin{array}{l}\text { Equivalent impedance of ac } \\
\text { source }\end{array}$ & $0.116 \Omega+\mathrm{j} 0.0091 \mathrm{H}$ & \\
Transformer ratio & $220 / 167 \mathrm{kV}$ & \\
$\begin{array}{l}\text { Transformer leakage } \\
\text { reactance }\end{array}$ & $0.15 \mathrm{p} . \mathrm{u}$. & \\
Power rating of MMC & $500 \mathrm{MVA}$ & \\
Rated dc voltage & $320 \mathrm{kV}$ & \\
Number of SMs in one arm & 200 & Redundancy ignored \\
Arm inductance & $0.6 \mathrm{H}$ & $0.06 \mathrm{H}$, When $500 \mathrm{~Hz}$ \\
SM capacitance & $10000 \mu \mathrm{F}$ & $1000 \mu \mathrm{F}$, when $500 \mathrm{~Hz}$ \\
Rated voltage of SM & $1.6 \mathrm{kV}$ & \\
Smoothing reactor & $50 \mathrm{mH}$ & \\
Grounded resistance & $0.29 \Omega$ & $U_{c e}=2500 \mathrm{~V}$ \\
IGBT module & $5 S \mathrm{NA} \mathrm{1200E250100}$ & $I_{c}=1200 \mathrm{~A}$ \\
\hline
\end{tabular}

$$
C_{0}=\frac{P_{s}}{3 k N \omega_{0} \varepsilon\left(U_{C}\right)^{2}}\left[1-\left(\frac{k \cos \varphi}{2}\right)^{2}\right]^{\frac{3}{2}}
$$

From eq.(10), it can be concluded that $C_{0}$ is inversely proportional to operating frequency under certain operating conditions.

From the information disclosed in [15], we can see that capacitor occupies almost half the volume of a SM. Thus, high frequency MMC can significantly reduce the volume of SMs therefore reduce the volume and weight of a $\mathrm{MMC}$.

\section{Results}

A three phase Modular Multi-level Converter was modeled in PSCAD/EMTDC. The system layout is shown in Fig. 3 and the parameters under different operating conditions are shown in Table 1.

\section{Accuracy verification of the proposed method}

To verify the proposed average value model of $\mathrm{MMC}$ can be applied for valve power loss, the valve power loss calculation results of fast model, detailed model and analytical method are shown in Table 2 . The results are

Table 2 Converter parameters and operation conditions

\begin{tabular}{llcl}
\hline & $\begin{array}{l}\text { Detailed } \\
\text { model }\end{array}$ & Fast model & $\begin{array}{l}\text { Analytical } \\
\text { method }\end{array}$ \\
\hline Switching frequency/Hz & 98.5 & 95.25 & 95 \\
Switching loss/kW & 17.23 & 17.01 & 36.24 \\
Conduction loss/kW & 444.78 & 442.20 & 440.00 \\
Total loss/kW & 462.01 & 459.21 & 476.24 \\
Simulation time/s & 187,045 & 502.2 & $<1 \mathrm{~s}$ \\
\hline
\end{tabular}


illustrated as the conduction loss and switching loss of a 50 MW 21-level MMC.

By comparison, the result of detailed model and fast model is shown in Fig. 4. $U_{d c}$ and $U_{s m \_t o t}$ are the DC voltage and the sum of the Submodule voltage respectively. $I_{d}$ and $I_{u p}$ are the d-axis component of the AC current and the upper arm current, respectively.
Apparently, the performance curve of the detailed model and fast model are basically in coincidence. The error of the conduction loss, switching loss and total loss between fast model and detailed model is about 0.58, 1.29 and $0.61 \%$. Thus, it can be concluded that the fast model of MMC proposed in this paper can provide high accuracy in valve loss calculation. The running time of

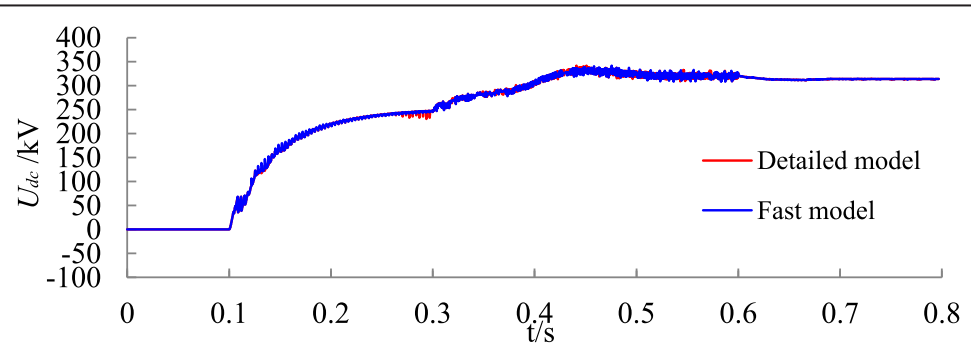

(a) DC voltage

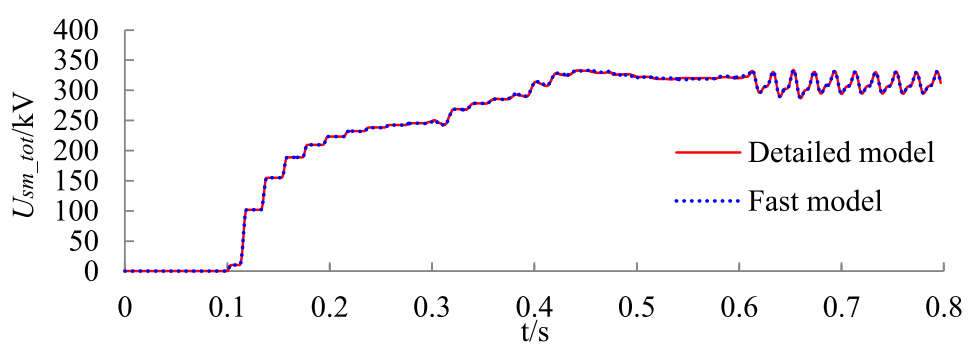

(b) The sum of the submodule voltage

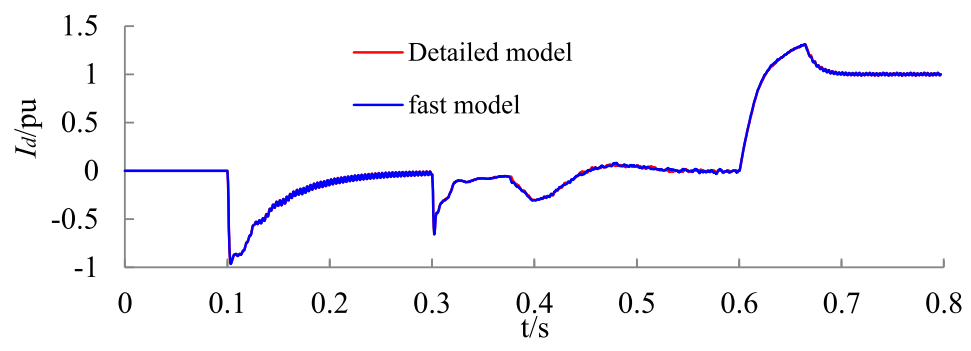

(c) The d-axis componentof the AC current

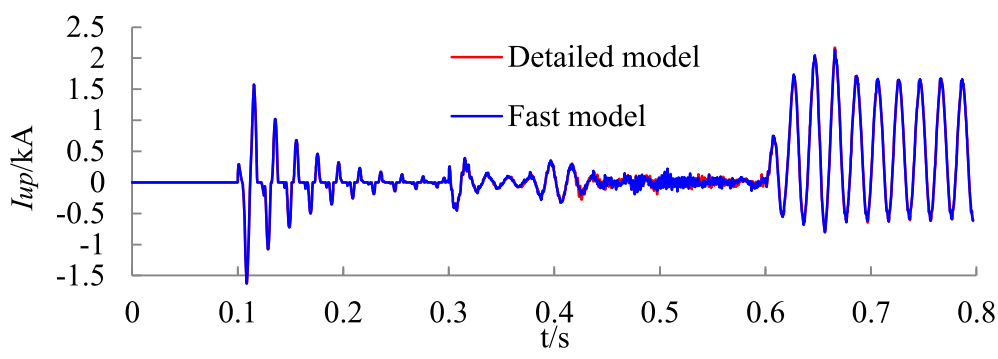

(d) The upper arm current

Fig. 4 Simulation results of Detailed Model and Fast Model 
the detailed model and fast model is $187,045 \mathrm{~s}$ and $502.2 \mathrm{~s}$ respectively, which can be concluded that the speed of the calculation process is significantly improved.

On the other hand, the analytical method can also produce an approximate value of conduction loss by applying mean and rms current of each arm. [6] Since switching occasions cannot be resented analytically, the switching loss is estimated by multiplying switching energy and average switching frequency. However, the turn-on and turn-off energy of IGBT and recovery energy of diode should depend on the instantaneous current and dc voltage instead of their mean and rms value. Thus, analytical method presents a large error, about $110 \%$, on switching loss.

Since the detailed model of MMC takes excessively long simulation time, the further study of this paper is based on the fast model shown in Fig. 1 (b).

\section{Verification of MMC models under different frequency}

Figure 5 shows the simulation results of the MMC under $50 \mathrm{~Hz}, 200 \mathrm{~Hz}$ and $500 \mathrm{~Hz}$ AC frequency while operating at the same power level.

Figure 5 (a) shows the instantaneous voltage of phase $\mathrm{A}$ and Fig. 5 (b) shows the active and reactive power output of MMC. It can be seen the voltage magnitudes and power output are exactly the same regardless of the different operating frequencies.
The simulation result of Fig. 5 verifies that the following power loss and comparison of MMC under different operating frequency are carried under same boundary conditions. The only variable is the operating frequency of MMC.

\section{Power loss of each device in a SM}

Valve power loss of four typical operation conditions for an MMC, namely, $(P, Q)=(1,0),(-1,0),(0,1),(0,-1)$ are analyzed in this section. Under each condition, the power loss distribution of each IGBT and diode in a SM is different.

Figure 6 shows the calculated power loss of $\mathrm{SM}_{1}$ on upper arm of phase A under four rated conditions at different AC frequencies. The conduction loss of devices is illustrated in dark grey color and switching loss in light grey.

Figure 6 (a)-(c) show that under the condition of $(P, Q)=(1,0)$, power loss of the lower $\operatorname{IGBT}\left(T_{2}\right)$ constitutes the majority of power loss of a SM. Under the condition of $(P, Q)=(-1,0)$, power loss of $D_{2}$ is significantly higher than the other three semiconductor switches. Power losses under the conditions of $(P, Q)=(0,1)$ and $(P, Q)=(0,-1)$ are more evenly distributed among the four semiconductor switches.

Figure 6 also shows that increase of the operating frequency only increases the switching power loss while the conduction loss is almost un-affected.
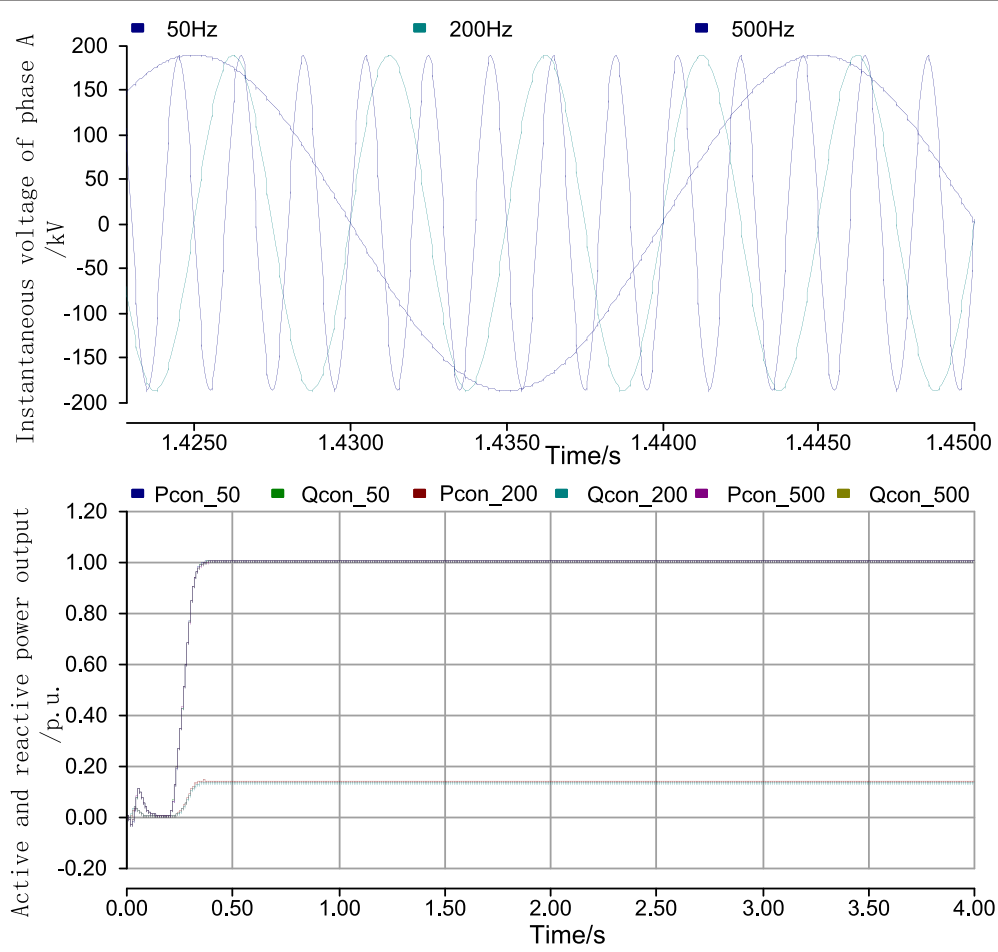

Fig. 5 Validation of normal operation for MMC under different frequency 


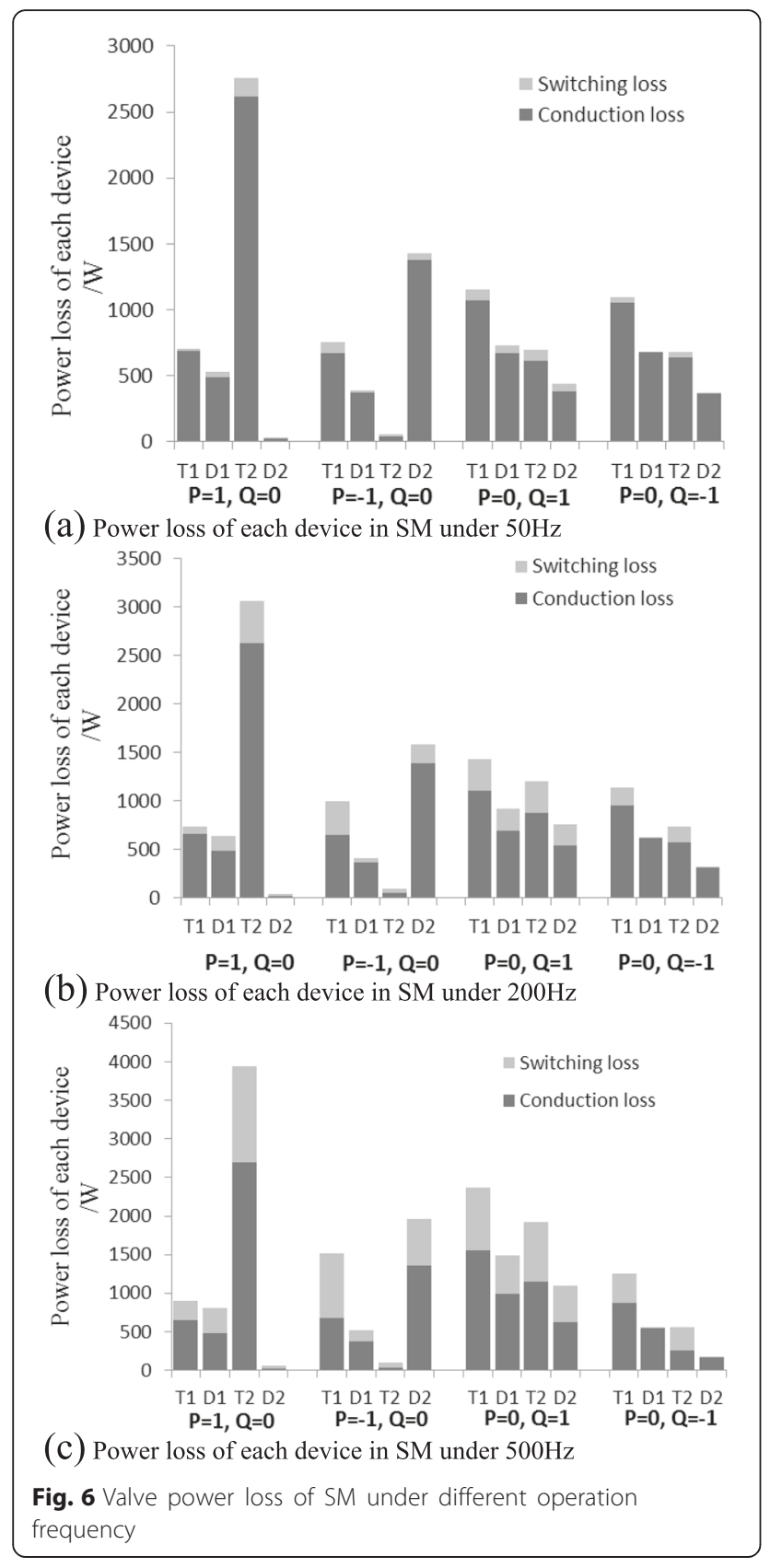

\section{Power loss of MMC with different active power levels}

This section calculate the power loss under different power output conditions by setting reactive power to be zero and changing the active power from -1.0 p.u. to $1.0 \mathrm{p}$.u. with step size of $0.1 \mathrm{pu}$. The power loss results and a second-order polynomial fitting curve between power output and power loss are shown in Fig. 7.

Comparison between Fig. 7 (a) and (b) shows the power loss of a MMC is higher at inverting mode than rectifying mode. Figure 7 also shows the relationship of

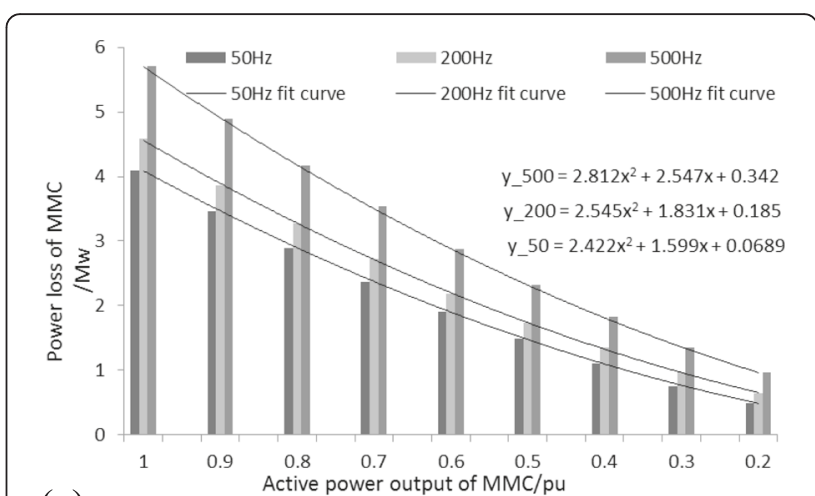

(a) MMC works as an inverter (value of $\mathrm{P}$ is positive)

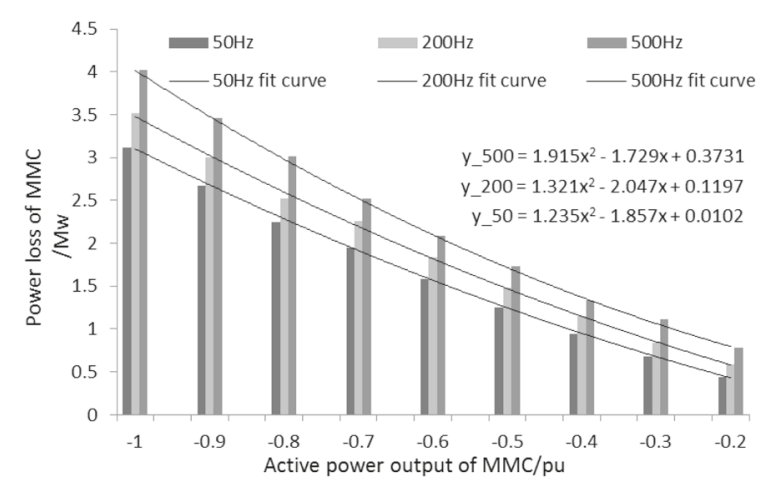

(b) $\mathrm{MMC}$ works as a rectifier (value of $\mathrm{P}$ is negative)

Fig. 7 Valve power loss of MMC under different power output

the power loss and the active power follows a secondorder polynomial.

Figure 8 shows the percentage of valve power loss power versus the corresponding active power level of the 201-level MMC with power rating of $500 \mathrm{MW}$.

The total power loss at rated power is $4.097 \mathrm{MW}$ at $50 \mathrm{~Hz}$ AC frequency, which is approximately $0.8 \%$ of rated power. With AC frequency increased up to $200 \mathrm{~Hz}$ and $500 \mathrm{~Hz}$, the power loss ratio increased up to 0.95 and $1.2 \%$ respectively.

\section{Discussion}

To further illustrate the relationship between valve power loss and operating frequency, operating frequency of MMC is varied from $50 \mathrm{~Hz}$ to $1000 \mathrm{~Hz}$ at a step of $50 \mathrm{~Hz}$. Figure 9 (a) and (b) respectively shows the average equivalent switching frequency and total valve power loss of MMC. The equivalent switching frequency is defined as:

$$
f_{s w \_a v g}=\frac{1}{T_{0}} \cdot \frac{1}{6 N} \cdot\left[\sum_{j=1}^{6} \sum_{j, i=1}^{N}\left(g_{s w_{-} T 1}(i)+g_{s w_{-} T 2}(i)\right)\right]
$$

In (11), $g_{s w_{T} T 1}$ and $g_{s w-T 1}$ is the number of switching instances of IGBT1 and IGBT2 in one sub-module, 


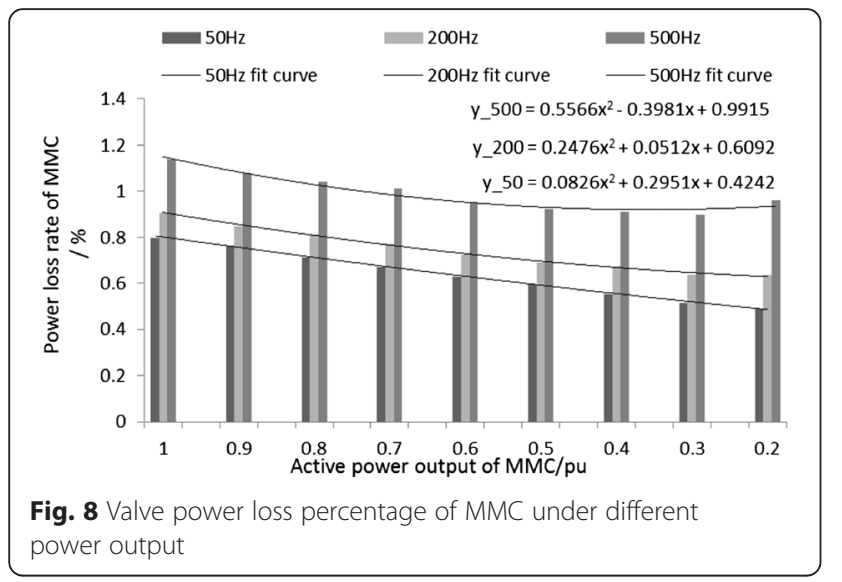

during time period $T_{0} . T_{0}$ is selected to be $1 \mathrm{~s}$ to take into effect that switching pattern of a sub-module varies from one fundamental cycle to another fundamental cycle.

It can be seen from Fig. 9 (a) that the equivalent switching frequency increases linearly with operating $\mathrm{AC}$ frequency. And switching frequency of a MMC is about 1.8 times of operating $\mathrm{AC}$ frequency with the nearest level control modulation and voltage balancing control [21].

Figure 9 (b) shows switching loss also increases linearly with the increasing of operating frequency while conduction loss remains almost unchanged. Thus, total valve power loss would increase linearly with operating frequency. At the operating frequency of $1 \mathrm{kHz}$, the switching loss is almost the same as the conduction power loss, making the total power loss of a MMC up to $1.6 \%$.

We can empirically conclude from Fig. 9 that a MMC operating at $500 \mathrm{~Hz} \mathrm{AC}$ frequency will increase the total power loss by $40 \%$ while the size of ac inductors and sub-module capacitor can be reduced approximately by 10 times.

\section{Conclusions}

A fast electro-magnetic simulation model of MMC is developed for accurate power loss. It can obtain almost identical simulation results as the detailed switch model while simulation speed can be improved by approximately 10,000 times.

A more accurate program for estimating valve power loss of MMC and junction temperature of devices is proposed, by linking PSCAD/EMTDC and Matlab. The accuracy of power loss calculation is verified by comparison with detailed model of MMC.

Relationships between power losses, the power transfer level and operating frequencies are presented and fitted, with a case of 201 -level MMC working at $50 \mathrm{~Hz} \sim 1000 \mathrm{~Hz}$.

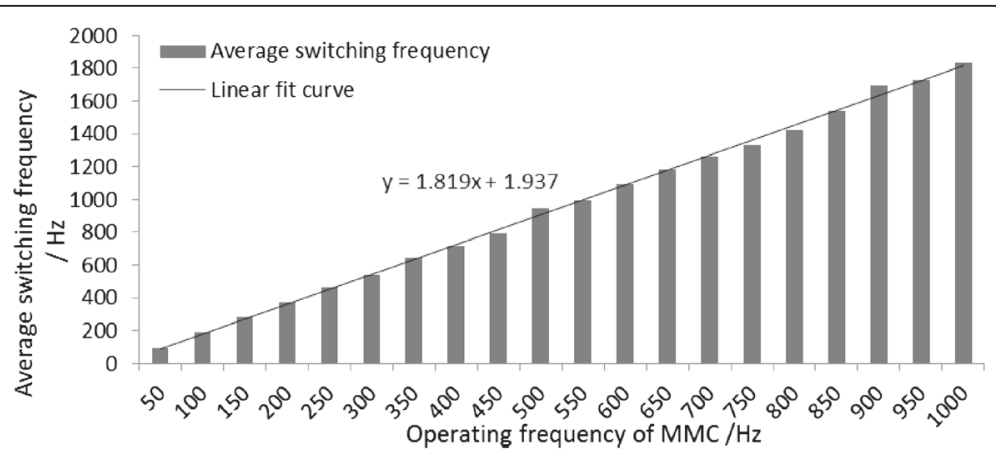

(a) Average switching frequency of $\mathrm{MMC}(\mathrm{P}=1.0, \mathrm{Q}=0)$

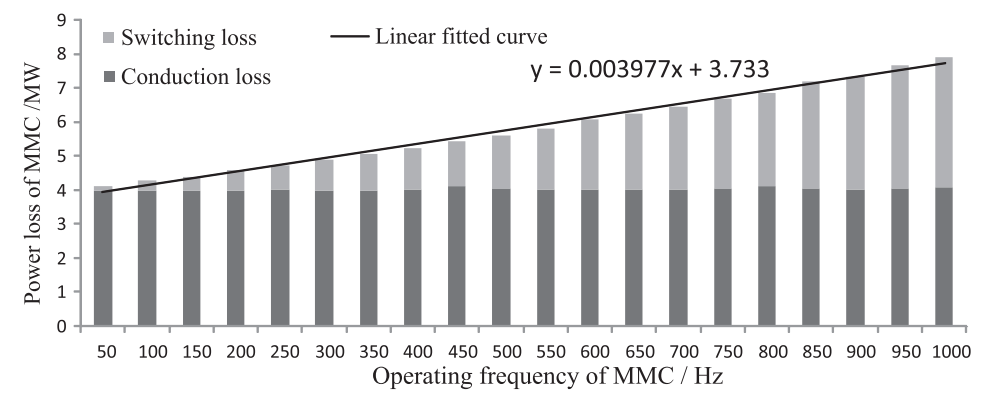

(b) Valve power loss of MMC ( $\mathrm{P}=1.0, \mathrm{Q}=0)$

Fig. 9 Valve power loss of MMC under different operating frequency 
Analysis shows that compared with $50 \mathrm{~Hz}$ operation, the valve power loss of MMC increased by 12, 40 and $93 \%$ under $200 \mathrm{~Hz}, 500 \mathrm{~Hz}$ and $1000 \mathrm{~Hz}$. Since the volume of arm inductor, SM capacitor and transformer of an MMC can be reduced inversely proportional to the operating frequency. Thus, MMC operating at higher frequency will be more competitive than typically 50/ $60 \mathrm{~Hz}$ MMC for potential applications in offshore frontto- front connected dc-dc converters.

\section{Appendix}

\section{Conduction losses of IGBT and diode}

Denote the on-state voltage as $U_{D}$ for diodes and $U_{c e}$ for IGBTs. The conduction loss can be evaluated mathematically as follows:

$$
\begin{aligned}
& P_{T c o n}=U_{c e} \cdot I_{c}=\left(R_{T} \cdot I_{c}+U_{c e 0}\right) \cdot I_{c} \\
& P_{D c o n}=U_{D} \times I_{D}=\left(R_{D} \times I_{D}+U_{D 0}\right) \times I_{D}
\end{aligned}
$$

Where $U_{\text {ce0 }}$ and $U_{\mathrm{D} 0}$ are respectively the threshold voltages for IGBT and diode. $R_{\mathrm{T}}$ and $R_{\mathrm{D}}$ are respectively the slope resistance for IGBT and diode.

\section{Switching losses of IGBT and diode}

IGBT switching energies $E_{\text {on }}$ and $E_{\text {off }}$ are normally quoted by the manufacturer as a function of current. Diode switching energies are referred to as recovery energy $E_{\text {rec }}$ and can also be expressed as a function of current.

$$
\begin{aligned}
& E_{o n}=\left(a_{1}+b_{1} \cdot I_{c}+c_{1} \cdot I_{c}{ }^{2}\right) \frac{U_{d c}}{U_{d c N}} \\
& E_{o f f}=\left(a_{2}+b_{2} \cdot I_{c}+c_{2} \cdot I_{c}{ }^{2}\right) \frac{U_{d c}}{U_{d c N}} \\
& E_{\text {Drec }}=\left(a_{3}+b_{3} \cdot I_{D}+c_{3} \cdot I_{D}{ }^{2}\right) \frac{U_{d c}}{U_{d c N}}
\end{aligned}
$$

The fitting parameters $a_{1}, b_{1}, c_{1}, a_{2}, b_{2}, c_{2}$ and $a_{3}, b_{3}$, $c_{3}$ can be found on the datasheet from manufacturer.

The total IGBT and diode switching losses are calculated by summing all the turn-on energies $E_{\mathrm{on}}$ and the turn-off energies $E_{\text {off }}$ or the recovery energies $E_{\text {rec }}$ over an integration time interval $T_{0}$.

$$
\begin{aligned}
& P_{\text {Tsw }}=\frac{1}{T_{0}} \cdot \sum_{j=1}^{m}\left(E_{\text {Ton }}(j)+E_{\text {Toff }}(j)\right) \\
& P_{\text {Drec }}=\frac{1}{T_{0}} \cdot \sum_{k=1}^{n} E_{\text {Drec }}(k)
\end{aligned}
$$

Where, $m$ is the number of switching circles (on and off) experienced by the IGBT during the integration time $T_{0}, n$ is the number of recovery occasions experienced by the diode during the integration time $T_{0}$.

\section{IGBT and diode cut-off losses}

The cut-off power losses are calculated as:

$$
\begin{aligned}
& P_{\text {Toff }}=U_{c e} \cdot I_{c \_l e a k}\left(T_{j}\right) \\
& P_{\text {Doff }}=U_{D} \cdot I_{D \_l e a k}\left(T_{j}\right)
\end{aligned}
$$

The value of leakage current can be found in datasheet from manufacturer and the typical value is $10 \mathrm{~mA}$ $\left(T_{j}=25{ }^{\circ} \mathrm{C}\right)$ and $60 \mathrm{~mA}\left(T_{j}=125{ }^{\circ} \mathrm{C}\right)$ for IGBT.

\section{About the Authors}

$\mathrm{F}$. Tao received the $\mathrm{B}$. Eng. degree in electrical engineering from the Huazhong University of Science and Technology, Wuhan, China, in 2007, where she is currently working as engineer in planning department of PowerChina Hubei Electric Engineering Corporation. His research interest is Design, planing and operation of power system.

Z.J. Xie received the Bachelor degree in electrical engineering from the Huazhong University of Science and Technology, Wuhan, China, in 2014, where he is currently working toward the B. Eng. degree. His research interest is modular multilevel converter and power flow control in dc grids. L. Zhao received the B. Eng. degree in electrical engineering from the Wuhan University, Wuhan, China, in 2011, where he is currently working as group leader in planning department of PowerChina Hubei Electric Engineering Corporation. His research interest is Design, planing and operation of power system.

C.H. Li received the B. Eng. degree in electrical engineering from the Huazhong University of Science and Technology, Wuhan, China, in 2009, where he is currently working toward the Ph.D. degree. His research interest is multi-terminal high-voltage direct-current control and dc grids. J. Cheng received the $B$. Eng. degree in electrical engineering from the Wuhan University, Wuhan, China, in 2010, where she is currently working as assistant manager in planning department of PowerChina Hubei Electric Engineering Corporation. His research interest is Design, planing and operation of power system.

J.Y. Wen (M'10),received his B. Eng. and Ph.D. degrees all in electrical engineering from Huazhong University of Science and Technology (HUST), Wuhan, China, in 1992 and 1998, respectively.

He was a visiting student from 1996 to 1997 and research fellow from 2002 to 2003 all at the University of Liverpool, UK, and a senior visiting researcher at the University of Texas at Arlington, USA in 2010. From 1998 to 2002 he was a director engineer in XJ Electric Co. Ltd. in China. In 2003 he joined the HUST and now is a professor at HUST. His current research interests include renewable energy integration, energy storage application, DC grid, and power system operation and control.

\section{Competing interests}

The authors declare that they have no competing interests.

\section{Authors' contributions}

FT proposed the fast valve power loss estimation method and drafted the manuscript. ZJX implemented the valve power loss estimation algorithm. LZ carried valve power loss estimation of MMC operating under different frequency. $\mathrm{CHL}$ designed the parameters of MMC operating under high frequency. JC verified the fast MMC simulation model. JYW designed the case studies. All authors read and approved the final manuscript.

\section{Acknowledgement}

This work was supported by the PowerChina Hubei Electric Engineering Corporation.

\section{Author details}

${ }^{1}$ PowerChina Hubei Electric Engineering Corporation, Wuhan, Hubei Province 430040, China. ${ }^{2}$ State Key Laboratory of Advanced Electromagnetic Engineering and Technology (Huazhong University of Science and Technology), Wuhan, Hubei Province 430074, China.

Received: 10 May 2016 Accepted: 10 May 2016 Published online: 20 June 2016 


\section{References}

1. Dorn, J., Huang, H., \& Retzmann, D. (2007). Novel voltage-sourced converters for HVDC and FACTS applications (pp. 1-6). Osaka: CIGRE Symposium.

2. Dorn, J., Huang, H., \& Retzmann, D. (2008). A new multilevel voltage sourced converter topology for HVDC applications (pp. 1-8). Paris, France: Proc. CIGRE.

3. Deore, S. R., Darji, P. B., \& Kulkarni, A. M. (2013). Switching function analysis of half- and full-bridge modular multi-level converters for HVDC applications. IET Generation, Transmission \& Distribution, 7(11), 1344-1356.

4. Jones, PS, Davidson, CC. "Calculation of power losses for MMC-based VSC HVDC stations," Power Electronics and Applications (EPE), 2013 15th European Conference on, Lille, 2013, pp. 1-10.

5. IEC 62751: 'Determination of power losses in voltage sourced converter (VSC) valves for high-voltage direct current (HVDC) systems'. 2013.

6. Oates, C, Davidson, C. "A comparison of two methods of estimating losses in the Modular Multi-Level Converter," Power Electronics and Applications (EPE 2011), Proceedings of the 2011-14th European Conference on, Birmingham, 2011, pp. 1-10.

7. Pang, H, Tang, G, He, Z. "Evaluation of losses in VSC-HVDC transmission system," Power and Energy Society General Meeting-Conversion and Delivery of Electrical Energy in the 21st Century, 2008 IEEE, Pittsburgh, PA, 2008, pp. 1-6.

8. Zhang, Y, Adam, GP, Lim, TC, Finney, SJ, Williams, B.W. "Voltage source converter in high voltage applications: Multilevel versus two-level converters," AC and DC Power Transmission, 2010. ACDC. 9th IET International Conference on, London, 2010, pp. 1-5.

9. Zygmanowski, M, Grzesik, B, Fulczyk M, Nalepa, R. "Analytical and numerical power loss analysis in Modular Multilevel Converter," Industrial Electronics Society, IECON 2013 - 39th Annual Conference of the IEEE, Vienna, 2013, pp. $465-470$.

10. Zhang, Z., Xu, Z., \& Xue, Y. (2014). Valve power lossValve power losses Evaluation Based on Piecewise Analytical Method for MMC-HVDC Links. IEEE Transactions on Power Delivery, 29, 1354-1362.

11. Rajapakse, A. D., Gole, A. M., \& Wilson, P. L. (2005). Electromagnetic Transients Simulation Models for Accurate Representation of Switching Losses and Thermal Performance in Power Electronic Systems. IEEE Transactions on Power Delivery, 20, 319-327.

12. Tu, Q., Xu, Z., "Power losses evaluation for modular multilevel converter with junction temperature feedback" 2011 IEEE Power and Energy Society General Meeting, San Diego, CA, 2011, pp. 1-7.

13. Peralta, J., Saad, H., Dennetiere, S., Mahseredjian, J., \& Nguefeu, S. (2012). Detailed and Averaged Models for a 401-Level MMC-HVDC System. IEEE Transactions on Power Delivery, 27, 1501-1508.

14. Jovcic, D., \& Lin, W. (2014). Multiport High-Power LCL DC Hub for Use in DC Transmission Grids. IEEE Transactions on Power Delivery, 29, 760-768.

15. Luth, T., Merlin, M. M. C., Green, T. C., Hassan, F., \& Barker, C. D. (2014). High-Frequency Operation of a DC/AC/DC System for HVDC Applications. IEEE Transactions on Power Electronics, 29, 4107-4115.

16. Adam, G. P., \& Williams, B. W. (2014). New emerging voltage source converter for high-voltage application: hybrid multilevel converter with dc side H-bridge chain links. IET Generation, Transmission \& Distribution, 8, 765-773.

17. Rohner, S., Bernet, S., Hiller, M., \& Sommer, R. (2010). Modulation, losses,and semiconductor requirements of modular multilevel converters. IEEE Trans Ind Electron, 57(8), 2633-2642.

18. Yu F, Lin W, Wang $X$ and Xie D. Fast voltage-balancing control and fast numerical simulation model for the modular multilevel converter, IEEE Transactions on Power Delivery, early access on IEEE Xplore.

19. ABB. 'Applying IGBTs'. pp. 1-40.

20. Qingrui, $T$, Zheng, $X$, Hongyang, $H$, Jing, Z. "Parameter design principle of the arm inductor in modular multilevel converter based HVDC", Power System Technology (POWERCON), 2010 International Conference on, Hangzhou, 2010, pp. 1-6.

21. Qingrui, T., Zheng, X., \& Lie, X. (2011). Reduced Switching-Frequency Modulation and Circulating Current Suppression for Modular Multilevel Converters. IEEE Transactions on Power Delivery, 26(3), 2009-2017.

\section{Submit your manuscript to a SpringerOpen ${ }^{\circ}$ journal and benefit from:}

- Convenient online submission

- Rigorous peer review

- Immediate publication on acceptance

- Open access: articles freely available online

- High visibility within the field

- Retaining the copyright to your article

Submit your next manuscript at $>$ springeropen.com 